\title{
Improving the Construction of Document Information Resources in CALIS System
}

\author{
Xiu-li Li ${ }^{1, a}$ \\ 1 JiLin Business And Technology College, ChangChun, China \\ a lixiulibb@126.com
}

Keywords: CALIS; resource construction; guarantee

\begin{abstract}
The CALIS system has completely changed the original service mode of library, and has made profound changes in library service, which requires perfecting the construction of CALIS document resources.
\end{abstract}

\section{Introduction}

CALIS system is the abbreviation of document support system for higher education in china. Under the leadership of the Ministry of education, CALIS integrates national investment, modern university digital library concepts, advanced technological means, rich literature resources and human resources in Colleges and universities, Go to the construction of higher education Chinese university digital library is the core of education literature joint security system, realize information resource co construction and sharing of knowledge, and to maximize the social benefits and economic benefits, for the service of higher education. The CALIS system has completely changed the original service mode of the library, and has made profound changes in the service of readers in the library, and formed a diversified and three-dimensional service system for readers, To provide efficient, comprehensive and diversified literature and information support for teaching, scientific research and key discipline construction in Colleges and universities, and provide high efficiency and personalized service for readers.

\section{Using CALIS to build literature information resources is of great significance}

\subsection{Change the management mode of University Library.}

Most of the University Libraries in our country are basically the self guarantee model of one school and one library, and the object of service is only limited to the readers and teachers in the school. The realization of CALIS requires the cooperation and coordinated development among the member libraries, and breaks the mode of self protection of various museums, and truly realizes the horizontal joint and common development.

\subsection{Promote the development and utilization of information resources, and raise the level of information services.}

The joint database provided by CALIS will collect bibliographic data and collection information of all member libraries, and its imported foreign database will greatly increase the library's available literature and information resources. CALIS the use of modern technology, establish a national university information resource sharing network, greatly improve the information service facilities and the level of the university library, which has undergone profound changes to the traditional manual way of service.

\subsection{To achieve co construction and sharing of resources.}

CALIS is a joint security system, and the museum itself is difficult to protect the literature, and can use the CALIS Central Museum and member Museum as the extension and expansion of the museum collection. Through the construction of the three level guarantee system, the libraries combine the characteristics of their respective disciplines, divide the work and focus on procurement, and jointly realize the rational distribution of the document resources nationwide. Through interlibrary lending, document delivery, coordination of procurement, online cooperative 
cataloging, self built database, etc., to completely make up for the lack of library collection, and achieve resource sharing.

\section{Characteristic collection construction of CALIS system}

Featured collection means the unique resources of a library, different from those of other libraries. The university library, it is in order to adapt to the characteristics of the service object and the school discipline construction, library resources have high academic value of literature related disciplines, information collected after the formation of the organization system, such as Bo, master thesis, academic seminar, academic research, academic monographs, literature compilation etc.. Under the network environment, the characteristic collection resources development thematic database, full text database, and provide the service, make it become the Internet information resources, can be used to maximize the value of the characteristic collection resources, widely to realize the sharing of information resources. Under the premise of considering the overall layout and collaboration of literature information resources, the university library should establish the characteristic collection resources according to the discipline advantages and the needs of the library and the demand characteristics of the service object. In the network information service competition environment, characteristic collection resources, good practical value high academic level can bring the brand for the library, is conducive to the development of Library in the information society of the survival and development of space.

\section{Digital collection construction of CALIS system}

Digital Collection refers to various database resources and various types of electronic publications that are planned, purchased, rented or developed by the library.

\subsection{Database. Including bibliographic databases and full-text databases.}

The university library collection are more used: "Tsinghua Tongfang academic journal" (full text), the National People's Congress "press" (full text), "China Dissertations Database" and CALIS development "in foreign books Union Catalog Database" etc.. University libraries can also collect relevant professional databases and databases issued abroad according to the needs of subject construction in our university. More data developers release CD ROMs and online versions, providing online database content update services. Database resources have the characteristics of large information capacity, full collection of data, multiple ways of rapid retrieval, small space occupation, and so on. It is very suitable for the needs of research readers.

\subsection{Electronic publications.}

It includes electronic publications, electronic books, multimedia audio-visual materials and application software in various forms of CD. They have a lot of printed literature incomparable function, such as multimedia data in graphic audio - visual form allows users to achieve the best learning, understand and accept the results, more application of University Library in this aspect is the teaching of foreign languages and computer data.

\subsection{Digital resources developed by the library.}

The university library can realize the digitization of the library document resources through the following ways:

4.3.1 Documents according to the original page scanning input stored as an image file, and index the image file through the index can find the required documents and display the page, but also use the OCR (optical Chinese characters recognition technology will transform it into a text format).

4.3.2 Inputs and stores the content of the document by text, and uses the full-text retrieval software to form a full-text retrieval database. It has the advantage of saving storage space and full text retrieval. University libraries should focus on developing digital resources that can be shared in the system on the basis of characteristic collection and division of labor, so as to avoid duplication of construction and waste of funds. Digital library is available for retrieval by the electronic reading room and the campus network, not only the embassy to a large extent hidden information resources 
more abundant, complete and diverse, but also improve the ease of use, expand the scope of use and sharing.

\section{Virtual collection resources construction of CALIS system}

The construction of virtual collection resources is network information resources. Relative to the museum's own possession of the physical collection, such as printed literature, not purchased databases, electronic publications, etc., for the museum's digital features collection, the virtual collection does not have the right to enjoy, but have the right to use. The rich information resources can greatly expand the scope of information collection of university library, to supplement the physical collection of resources, but also has the characteristics of distributed network information resources disorderly, too big and fast updates, and must be collected and the organization can put it into a system and the ease of use of resources. At present, there are mainly three ways to collect and organize network information resources in University libraries:

\subsection{Establish network information base.}

According to the needs of clients, determine the scope of the collection of information, the network information resources related, such as online publications, software, news, announcements and research institutions meeting specific web content collection, selection, download and establishment of information resources, to provide services in the local area network, in this way the SDI service has good effect.

\subsection{The establishment of network resources navigation library.}

Cyber source navigation service to close the museum service professional website, such as online databases, human science, research institutes, academic institutions, professional website of library website classification organization link to the museum homepage for readers to quickly visit the above website.

\subsection{Establish an online thematic index.}

That web information source URL compiled into the index, establish site index database, to help users find the Internet address of each server, and through the query to the URL to access the server to obtain relevant information.

\section{Summary}

Since the Internet era, the concept and scope of resource sharing have been further expanded, and the sharing of library resources can be realized between the libraries connected by the internet. The premise of the literature information resources sharing is to build, construction and development issues must be re understanding of the library literature information resource system from the height of the network construction and sharing of library information resources, every library should be integrated into the system of information resources and the information resources sharing service system. The document guarantee system can enjoy the service provided by this system and serve the teaching and scientific research of the college.

\section{References}

[1] Ma Yan. Promoting the construction of university literature resources with CALIS as the leader. Information resources construction.2003.

[2] Chen Haiyan. Construction of digital resources in the library document resource support system. Science and technology information development.2012. 